\title{
$\mathrm{TV}$ 뉴스 여성 앵커의 빨강색 의상 이미지에 관한 연구
}

\section{A Study on TV News Anchor Women's Red Clothing Image}

\author{
대전대학교 패션디자인 · 비즈니스학과 \\ 박사과정수료 정 지 연 \\ 교 수 이 은 경
}

Department of Fashion Design \& Business, Daejeon University

Dissertator : Ji yeun Jeong

Professor : Eun kyung Lee

목 차
I. 서론
II. 이론적 배경
III. 연구 방법
$\mathrm{IV}$. 연구 결과 및 고찰
$\mathrm{V}$. 요약 및 결론
참고문헌

\begin{abstract}
$<$ Abstract $>$
This study was motivated from the point that TV anchor women wore red clothing the most when they appeared at the broadcasting. For the analysis of clothing color, the main news programs of three local terrestial broadcasting systems were adopted, and the screen sources having been obtained for a year on the anchor women from January 2008 to December were classified by S/S, F/W. As the result, it was found out that the image was classified according to the inherent symbolic meaning of red color, and red color was frequently adopted for the happypassionate image. It is judged that the reason is red color clothing spotlights passionate, challenging and imposing image which anchor women have. It revealed that while investigating the relationship of coloration between red upper clothing and other clothing, the inner-wear white color of the red jacket, or of the black inner-wear was matched the most, regardless of season. It is judged that this is because the coloration of red and white, and of red and black give not only brilliant but also clear image.
\end{abstract}

주제어(Key Words) :TV뉴스(TV news), 여성 앵커(anchor women's), 빨강색 의상 이미지(red clothing image)

Corresponding Author : Eun Kyung, Lee, Department of Fashion Design \& Business, Daejeon University, 96-3 Youngun-Dong, Dong-Gu, Daejeon, 300-716, Korea Tel: +82-42-280-2464 Fax:+82-42-280-2460 E-mail: dream@dju.ac.kr 


\section{I. 서 론}

오늘날 현대인은 TV, 신문, 라디오, 인터넷 등의 다양한 매체를 통하여 새로운 정보를 접하고 있다. 그 중 TV뉴스는 영상과 음향을 통해 정보를 전달하기 때문에 다른 매체에 비 해 비언어적 요소인 색감, 표정, 동작 등의 비중이 크며 신속 성과 광역성, 속보성 등의 장점을 모두 가지고 있다.

TV뉴스는 신뢰성이 가장 중요한 요소로 이는 뉴스의 내용 뿐아니라 진행하는 앵커의 자질과 역할에 따라서 크게 좌우된 다. 따라서 앵커는 뉴스 프로그램에 적합한 언어구사, 음성, 태 도, 의상, 헤어, 메이크업 등을 갖추어 시청자들로부터 신뢰를 얻어야 한다. 앵커가 갖추어야할 많은 요소들 중 의상은 시각 적 이미지 형성에 중요한 요소라 할 수 있다. 의상은 앵커의 신 체적 외모를 돋보이게 하며 시청자들에게 좋은 이미지를 심어 줄 수 있는 수단이 된다. TV뉴스 프로그램이 본격적인 경쟁체 제에 돌입하면서 뉴스를 진행하는 여성앵커들의 패션 이미지 연출도 경쟁적으로 세련되어지고 화려해지기 시작하였다. 패 션 이미지란 의상의 색, 디자인, 재질 등에 따라 시청자에게 전 달되는 이미지를 뜻한다. 이 중에서도 특히 색은 앵커의 시각 적인 이미지를 형성할 뿐만 아니라 순간적으로 사람들의 감정 과 감각을 자극하여 오래도록 기억되게 하는 특성을 갖고 있기 때문에 앵커들에게 의상색은 매우 중요한 의미를 갖는다.

이처럼 앵커의 의상색에 관한 연구가 매우 필요함에도 지 금까지 이루어진 앵커에 관한 연구는 주로 앵커의 이미지 메 이킹에 관한 연구(정하나, 2003), 앵커에 대한 수용자 이미지 연구(김은경, 2001; 박찬민, 1991; 이영혜, 2005), 앵커의 패 션 이미지 변화에 관한 연구(박성희, 2004), 앵커의 메이크업 특성에 관한 연구(윤미영, 2005; 최희자, 2003)들 뿐으로 방 송사별 앵커의 의상색에 관하여 세부적으로 비교한 연구는 매우 미흡한 실정이다.

그동안 방송사별로 여성 앵커들이 착용한 의상색을 수집 하여 분석한 결과 유채색 중에서는 빨강색의 사용빈도가 가 장 높은 것으로 나타났다(이은경, 2010). 따라서 본 연구에서 는 빨강색 의상의 착용빈도가 왜 높은지, 시청자들에게 어떠 한 이미지를 줄 수 있는지 그리고 빨강색과 가장 잘 매치되 는 이너웨어 색은 어떤 것인지 연구함으로써 방송사가 추구 하는 앵커 이미지 연출과 일치하는지 등을 밝혀보고자 한다. 이를 위해 빨강색의 일반적 이미지 특성을 문헌과 선행연구 를 통해 알아본 후, 앵커들이 빨강색 의상을 착용한 사례를 중심으로 방송사별 시즌별 빨강색 상의 재킷의 착용빈도 분 포, 재킷과 이너웨어와의 배색 분포 등을 고찰하고자 한다. 이는 TV뉴스 프로그램의 적합한 이미지 형성에 그리고 앵커 자신만의 독특한 이미지를 구축하는데 기본 자료로 활용할 수 있도록 하는데 목적이 있다.

\section{II. 이론적 배경}

\section{1. 빨강색의 특성 및 이미지}

\section{1) 빨강색의 정의와 특성}

빨강색은 한국산업규격(KS A 0011)에서 색 이름을 규정 함에 있어서 중요한 기본색의 하나로서 제시되었다. 대응영 어로는 Red, 약호로는 R, 수식어로는 노랑 띤 빨강 (yellowish red)과 보라 띤 빨강(purplish red)이 있다. 한자어 로는 적색(赤色), 비색(緋色), 홍색(紅色), 강색(降色)이라 하는 데 순수한 붉은색은 순홍색(純紅色), 짙으면서 다른 것이 거 의 섞이지 않았다는 뜻으로는 진홍(㝵紅), 선홍(鮮紅), 제홍 (祭紅)이라고 한다(하용득, 1992, p. 131).

빨강은 따뜻한 느낌을 준다고 해서 난색계로 취급하며, 파랑과 같은 위치에 나란히 있을 때 조금 앞쪽에 있는 것처 럼 보이기 때문에 전진색(前進色)이라고도 한다(김민주, 2002). 원경미와 김영인(2001)은 빨강색의 하위색명으로 cardinal red, hot red, reum red, signal red, vintage red 를 꼽았으며, 계통색명으로는 dark red, dull purplish red가 있다고 하였다. 국내 패션업계에서는 $5 \mathrm{R}$ 의 명도 4 , 채도 9 의 strong한 색조의 순색인 빨강을 가장 많이 활용하고 있다(원 경미, 김영인, 2001). 물리적 측면에서의 빨강은 가시(可視) 스펙트럼에서 620-780 mm의 파장을 가지는데 스펙트럼의 긴 파장 부분에 많은 방사 에너지가 포함되어 있어 붉은 빛 으로 보인다(김학성, 1995, p. 67). 또한 가시광선 중 파장이 가장 길고 에너지가 가장 낮으며 빛에 오랫동안 노출 되지 않는 사람이 가장 먼저 인식하게 되는 난색 중 가장 뜨겁고 적외선에 가까운 색이다(Marshall, 1988).

\section{2) 빨강색의 상징 이미지}

색에 대한 이미지는 나라, 생활양식, 문화적 배경, 지위, 개인의 환경, 경험 등에 따라서 다르게 나타나기도 하지만, 사람들이 느끼는 색의 감정은 공통적으로 비슷한 현상을 보 인다. 이러한 감정들이 사회적으로 일반화되면서 특정한 상 징적 이미지를 갖게 된다(김민신, 2007).

일반적으로 빨강색은 불, 열정, 사랑 등의 이미지를 상징 하는데 자신감, 힘참, 쾌활함, 명랑함, 생동력 넘침 등 긍정적 인 행동 이미지를 나타낸다. 때문에 운동선수의 유니폼이나 응원복에 사용되어 정열, 스피드, 에너지, 활력 등을 표현한 다(Breaem, 2002, p. 89). 또한 빨강색은 왕의 복식, 천주교 교황과 주교들의 의상색으로 사용됨으로써 권위와 신성함을 상징하기도 한다. 기본적으로 위험이나 정지, 금지를 뜻하는 안전색의 표시로 주로 쓰이며 도로의 교통신호, 통행금지, 붉은 깃발 등에 사용된다. 이는 빨강색의 특성을 이용하여 
시각적으로 도출되어 보이고 다른 색보다 뚜렷하게 색을 볼 수 있기 때문이다(Heller, 2002, p. 23). 부정적 이미지의 빨 강색은 범죄, 복수, 전쟁, 악마, 증오, 위험, 정지 등을 나타내 는 상징적 이미지를 가지고 있다. 강렬하면서도 노골적인 색 으로 여겨 유치, 야만, 비속, 위험으로 해석되었으며 오늘날 에도 에로티시즘을 급진적으로 표현할 때 빨강색을 사용하 기도 한다(Marshall, 1988).

\section{3) 빨강색의 색채 이미지}

색채 이미지는 시각적 이미지와 언어적 이미지가 통합 된 것으로 색채와 언어는 본래 이질적인 것이지만, 색채는 고유 의 언어를 연상하게 한다. 이러한 언어의 연상은 색채를 보 았을 때 나타나는 심리적 동요이며, 국가, 환경, 문화가 다르 더라도 어떤 공통적인 이미지가 존재하고 있다. 색채 이미지 분석은 색채 이미지와 언어 의미 사이의 평형을 찾아내어 색 채를 통한 인간의 심리, 감정을 보다 잘 표현하기 위한 방법 이다(장하나, 2003). Kobayashi(1987)의 색채 이미지 척도 개발에 대한 연구에서 빨강색이 색조에 따라 나타내는 이미 지를 살펴보면 〈표 1〉과 같다(Kobayashi, 1987).

〈표 1〉 빨강색의 색조에 따른 이미지

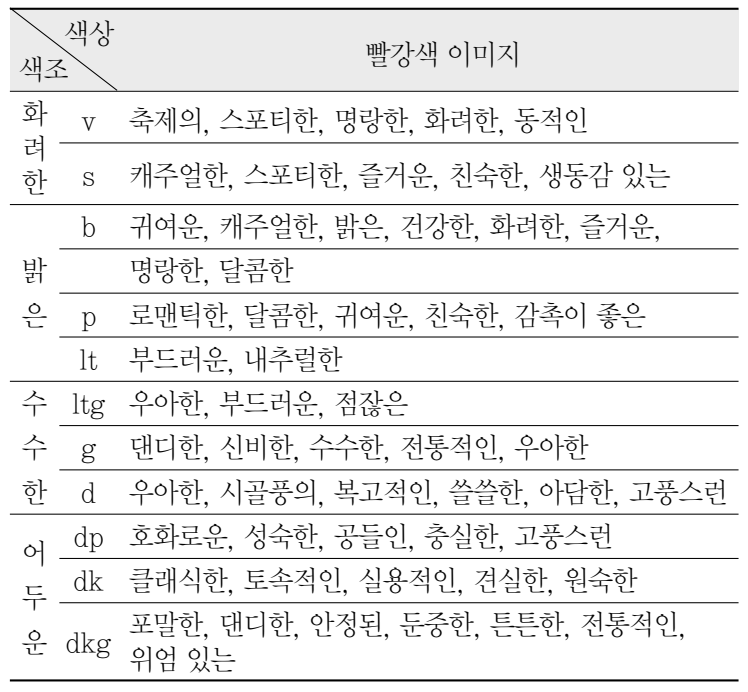

\section{TV뉴스 앵커의 역할 및 의상 특성}

뉴스는 신뢰성이 중요한 방송매체로 신뢰성은 뉴스 전달 자인 앵커의 신뢰도와도 연결되어 있다. 때문에 앵커의 용 모, 음성, 눈빛, 의상, 헤어, 메이크업 등에 따라 뉴스 내용의 전달 정도가 달라질 수 있다. 방송 의상색에 관한 중요성은 1980 년 흑백 TV가 컬러화되면서 부각되기 시작하였다. 색에 대한 관심과 인지도가 높아지면서 시청자들은 점차 색의 다 양화와 고급화를 요구하게 되었고 이로 인해 방송 의상색에
대한 전문적인 지식이 필요하게 되었다. TV뉴스에서의 앵커 는 자신이 가지고 있는 기본적 외모에 대해 세밀히 분석한 후, 방송 프로그램에 적합한 신선하고 새로운 이미지를 시청 자들에게 인식시켜야 한다.

TV뉴스 앵커의 의상 특성을 한마디로 요약하면 단순함과 지성미이다. 뉴스 앵커는 프로그램을 구성하는 한 요소라 할 수 있기 때문에 지나친 차림으로 시청자들에게 시각적으 로 흥미를 유발시키는 것은 정확하고 신뢰도 높은 뉴스전달 에 방해가 될 수 있다. 따라서 복잡한 재킷 라인, 산만한 디 테일, 시각적으로 눈에 불편을 주는 색 등은 뉴스 의상으로 부적합하다. 또한 뉴스는 일반 프로그램과는 다르게 얼굴형 에 따른 디자인과 상체 위주의 디테일에 신경을 써야 한다는 특징을 가지고 있다. 따라서 뉴스 앵커의 의상은 기본적인 디자인 요소에 차별성을 두고, 유행에 대한 수용정도도 빠르 게 반응하여 섬세하고 신중한 의상기획이 이루어져야 할 것 이다.

\section{III. 연구 방법}

빨강색의 특성 및 이미지, TV뉴스 앵커의 역할 및 의상 특성에 관한 것은 선행연구와 문헌을 토대로 고찰하였다. 빨 강색의 일반적 이미지 분석은 빨강색을 사용한 여러 분야의 사진 자료 100 여점을 모아 인공물과 자연물로 나눈 후 패션 상품, 일반 제품, 인테리어용품, 회화 등으로 분류하였다. 이 들을 두 가지의 감성축(행복한-불행한, 열정-냉정)을 이용하 여 분석하였는데 감성축 설정을 위한 형용사어는 신수길, 박 미자, 한광희와 황상민(1998)의 연구에서 우리말 형용사의 대표어쌍 중 빨강색 이미지를 분류하는데 용이한 형용사어 를 선정하여 사용하였다(신수길 외, 1998).

여성 앵커의 의상색 분석은 국내의 지상파 방송3사로 시 청률이 가장 높고 각 방송사를 대표하는 메인 뉴스 프로그램 인 $\mathrm{KBS}$ 9시뉴스, $\mathrm{MBC}$ 뉴스데스크, SBS 8시뉴스를 선정하 였다. 2008년 1월부터 12월까지 1년간 여성 앵커들의 빨강색 재킷 착용사진 자료 총114점을 수집한 후, 이를 $\mathrm{S} / \mathrm{S}, \mathrm{F} / \mathrm{W}$ 로 분류하여 분석하였다. 빨강색의 범위는 색의 3 속성에 따른 표시방법으로(우석진, 2005, p. 13) 한국 산업규격(KSA0062) 의 먼셀 표색계를 기준으로 규정된 10RP 10R의 범위에서 앵커가 빨강색 재킷을 착용한 사진을 선택하였다. 선택 된 색은 Adobe Photoshop 7.0 프로그램을 이용해 추출하였으 며, 추출된 색은 Munsell Conversion 프로그램을 이용해 $\mathrm{HV} / \mathrm{C}$ 로 변환한 후 분석하였다. 


\section{IV. 연구 결과 및 고찰}

\section{1. 빨강색의 일반적 이미지 분석}

빨강색을 사용한 패션상품, 일반제품, 인테리어용품, 회화 등 다양한 분야의 사진 자료 100 여점을 선택하여 행복한-불 행한, 열정-냉정의 두 가지의 감성축을 이용해 빨강색 이미 지를 분석한 결과는 〈그림 1)과 같다. 분석 결과, 빨강색이 이미지를 형성할 때는 색조의 영향보다는 빨강색 자체가 가 지고 있는 고유한 상징적 의미가 더 크게 영향을 끼치는 것 으로 나타났고, 또 빨강색은 행복한-열정적 이미지로 가장 많이 사용되고 있음을 알 수 있었다.

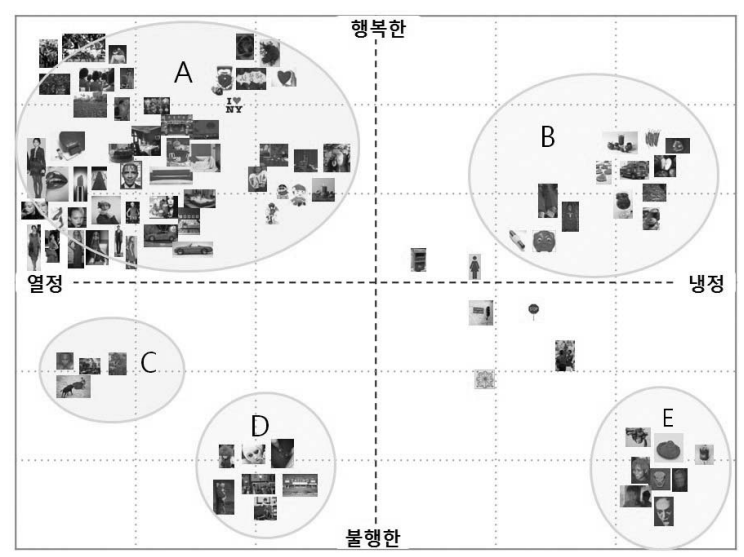

〈그림 1〉 감성축에 따른 빨강색 이미지 분포

빨강색 이미지는 크게 5 개의 영역으로 분류할 수 있었는 데 각 영역에 해당하는 이미지어는 〈표 2〉와 같다. 영역 $\mathrm{A}$ 는 매우 긍정적인 이미지로 앵커들에게 매우 필요하고 적절한 이미지라고 생각된다. 그러나 빨강색은 C, D, E 영역에서 보 듯 부정적인 이미지도 많이 갖고 있으므로 방송 의상색으로 선택시 명도, 채도, 배색 등 많은 부분을 고려해야 한다.

〈표 2〉 빨강색의 형용사 이미지어

\begin{tabular}{cl}
\hline 영역 & \multicolumn{1}{c}{ 빨강색의 형용사 이미지어 } \\
\hline $\mathrm{A}$ & 행복한, 열정적인, 자신감 있는, 희망찬, 기쁜 \\
\hline $\mathrm{B}$ & 권위적인, 힘이 있는, 매운, 냉정한 \\
\hline $\mathrm{C}$ & 충동적인, 전투적인, 공격적인, 흥분된 \\
\hline $\mathrm{D}$ & 퇴폐적인, 성적, 음란한, 불행한 \\
\hline $\mathrm{E}$ & 악마스러운, 반항적인, 분노한 \\
\hline
\end{tabular}

\section{TV 뉴스 여성 앵커의 빨강색 상의 특성}

1) 전체 색상 분포

수집된 전체 빨강색 상의의 수는 총 114 점이며, $\mathrm{S} / \mathrm{S}$ 시즌 에는 $54 \%, \mathrm{~F} / \mathrm{W}$ 시즌에는 $46 \%$ 로 $\mathrm{S} / \mathrm{S}$ 시즌이 약간 더 많이 빨

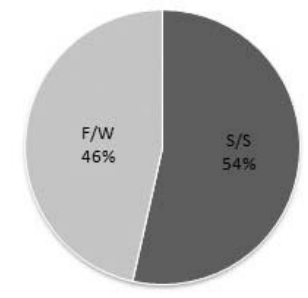

〈그림 2〉시즌별 빨강색 상의 분포

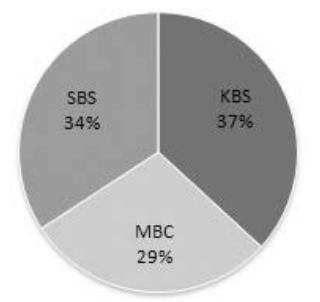

〈그림 3〉방송사별 빨강색 상의 착용 분포

강색을 착용하는 것으로 나타났다〈그림 2〉.

각 방송사별 TV뉴스 앵커의 빨강색 상의의 착용 분포는 〈그림 3〉과 같다. $\mathrm{KBS}$ 는 빨강색 상의의 선택 빈도가 $37 \%$, $\mathrm{SBS}$ 는 $34 \%, \mathrm{MBC}$ 는 $29 \%$ 로 $\mathrm{KBS}$ 가 다른 방송사 보다 빨강 색 상의의 착용빈도가 높게 나타났다.

TV뉴스 앵커의 시즌에 따른 빨강색 상의의 선택 빈도를 살펴보면 〈그림 4〉와 같다. $\mathrm{KBS}$ 는 빨강색 상의를 $\mathrm{S} / \mathrm{S}$ 시즌보 다는 $\mathrm{F} / \mathrm{W}$ 시즌에 더 많이 선택하였으며, $\mathrm{MBC}$ 는 $\mathrm{S} / \mathrm{S}$ 시즌에 빨강색 상의를 보다 많이 선택하였음을 알 수 있었다. SBS는 $\mathrm{S} / \mathrm{S}$ 시즌이 빨강색 상의의 선택 빈도가 약간 높지만 $\mathrm{F} / \mathrm{W}$ 시 즌과 큰 차이는 보이지 않았다.

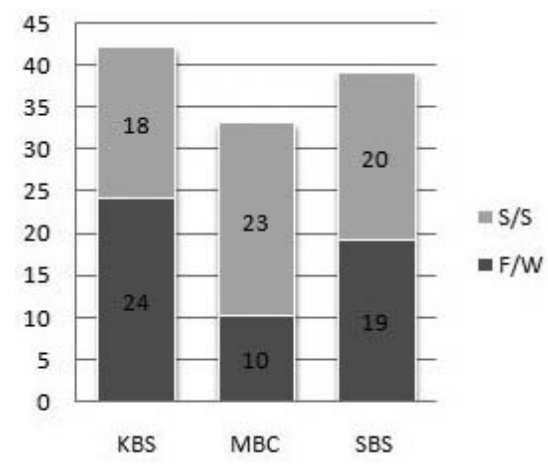

〈그림 4〉 시즌별 빨강색 상의 착용빈도 분포

2) 색상 분포의 특성

TV뉴스 여성 앵커가 착용한 빨강색 상의는 전체 색상 중 $32 \%$ 를 차지하고 있었다. 빨강색 상의 전체 평균 색상값은 $6.7 \mathrm{R}$, 명도는 4.5 채도는 11.4 로 나타났다. 시즌별로는 $\mathrm{S} / \mathrm{S}$ 시 즌에는 평균 색상값 $7.2 \mathrm{R}$, 명도 4.8 채도 12.3 이며, $\mathrm{F} / \mathrm{W}$ 시즌 
에는 평균 색상값 $6.1 \mathrm{R}$, 명도 .2 채도 10.4 로 나타났다. $\mathrm{S} / \mathrm{S}$ 시즌에 나타난 빨강색 상의는 $\mathrm{F} / \mathrm{W}$ 시즌 빨강색보다 주황계 열에 더 가깝게 위치되어 있음을 알 수 있었다. 두 시즌 모두 명도는 중명도에 속하며 시즌별 큰 차이는 보이지 않았고, 채도는 $\mathrm{S} / \mathrm{S}$ 시즌이 $\mathrm{F} / \mathrm{W}$ 시즌보다 더 높게 나타났다.

방송사별 $\mathrm{S} / \mathrm{S}$ 시즌 평균 색상값을 살펴보면〈표 3〉과 같 다. $\mathrm{MBC}$ 뉴스 앵커의 빨강색이 색상, 명도, 채도에서 타 방 송사 앵커보다 높게 나타났다. 방송사 모두 주황색 계열의 색을 많이 띠고 있었으며, S/S시즌에는 v, p, vp 톤 등이 많 이 사용되었음을 알 수 있었다.

〈표 3〉S/S시즌의 방송사별 평균 색상값

\begin{tabular}{|c|c|c|c|}
\hline 방송사 & KBS & $\mathrm{MBC}$ & SBS \\
\hline 색상 & 7R 4.4/9.8 & 7.7R 5.6/14.1 & $6.8 \mathrm{R} 4.3 / 12.5$ \\
\hline
\end{tabular}

방송사별 $\mathrm{F} / \mathrm{W}$ 시즌 평균 색상값을 살펴보면 〈표 4〉와 같다. $\mathrm{KBS}$ 와 $\mathrm{SBS}$ 뉴스 앵커의 빨강색 상의 색상값은 $5.9 \mathrm{R}$ 로 동일하지만 명도와 채도값은 차이를 보이고 있다. $\mathrm{MBC}$ 의 색 상값은 $7.2 \mathrm{R}$ 로 주황색 계열에 가까우며 채도가 다른 방송사 보다는 높게 나타났다. 방송사 모두 F/W시즌에는 s, lgr, l, $\mathrm{gr}, \mathrm{dl}, \mathrm{dp}$ 톤의 빨강색 의상을 선택하였음을 알 수 있었다.

〈표 4〉 F/W시즌의 방송사별 평균 색상값

\begin{tabular}{|c|c|c|c|}
\hline 방송사 & KBS & $\mathrm{MBC}$ & SBS \\
\hline 색상 & $5.9 \mathrm{R} 4.4 / 9.4$ & 7.2R 4.4/13.1 & $5.9 \mathrm{R} 3.7 / 10.3$ \\
\hline
\end{tabular}

\section{TV 뉴스 여성 앵커의 빨강색 상의 시즌별 배색 특성}

TV뉴스 앵커가 빨강색 상의와 매치시켜 입은 이너웨어에 대한 전체 시즌별 배색 분포를 살펴보면 〈그림 5)와 같다. $\mathrm{S} / \mathrm{S}$ 시즌에는 흰색과의 배색이 $62 \%$ 로 가장 많고 다음이 검정 색 $18 \%$, 노랑색 $3.2 \%$ 순이다. 배색을 하지 않고 빨강색만 착 용한 경우도 $9.8 \%$ 나 되었다. $\mathrm{F} / \mathrm{W}$ 시즌에는 흰색과의 배색이 $49 \%$ 로 가장 높았는데 $\mathrm{S} / \mathrm{S}$ 시즌보다는 흰색이 적게 사용되었 음을 알 수 있었다. 다음은 검정색 $24.5 \%$, 노랑색 $5.6 \%$ 로 이

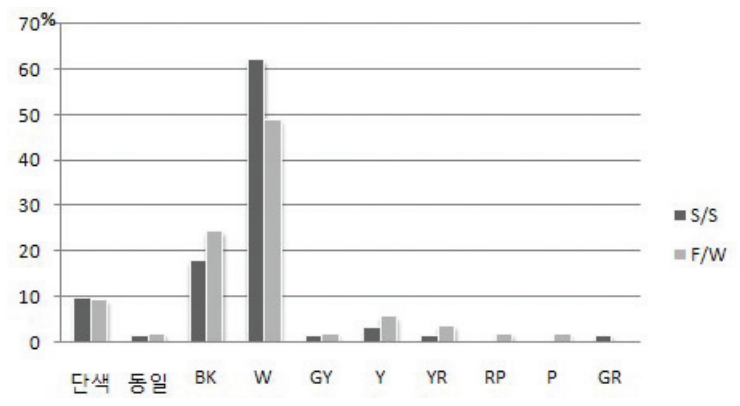

〈그림 5〉전체 시즌별 배색 분포

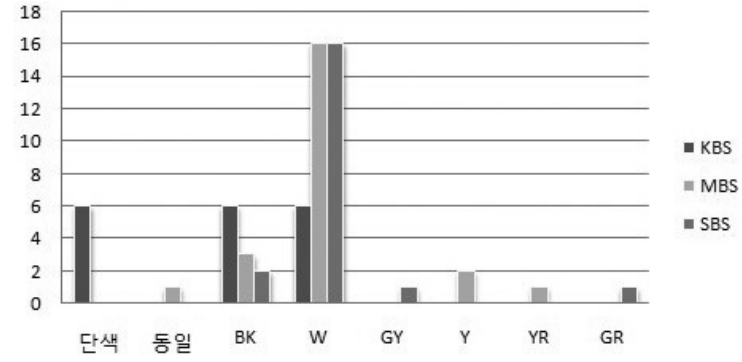

〈그림 6〉S/S시즌 빨강색 상의의 배색 분포

러한 배색은 $\mathrm{S} / \mathrm{S}$ 보다 높게 나타났다. 빨강색만 착용한 경우 는 $9.4 \%$ 로 $\mathrm{S} / \mathrm{S}$ 와 별 차이가 없었다.

$\mathrm{S} / \mathrm{S}$ 시즌에 나타난 방송사별 뉴스앵커의 빨강색 상의와 매치시켜 입은 이너웨어와의 배색 분포를 살펴보면〈그림 6)과 같다.

$\mathrm{S} / \mathrm{S}$ 시즌 $\mathrm{MBC}$ 와 $\mathrm{SBS}$ 앵커는 빨강색과 흰색과의 배색이 높은 분포를 보이며, $\mathrm{KBS}$ 는 빨강색만 착용한 경우, 검정색, 흰색 배색 등이 동일한 분포를 나타내고 있었다. 방송3사 모 두 대체적으로 흰색과 검정색 배색이 두드러졌는데 빨강색 상의와의 매치는 무채색과의 배색이 선명하고 단정한 인상 을 줄 수 있기 때문으로 분석된다.

$\mathrm{F} / \mathrm{W}$ 시즌에 나타난 방송사별 뉴스앵커의 빨강색 상의와 매치시켜 입은 이너웨어와의 배색 분포를 살펴보면 〈그림 7〉 과 같다. 방송3사 앵커 모두 흰색과의 배색이 가장 높게 나타 났는데 그 중 $\mathrm{KBS}$ 가 가장 높았다. 다음으로는 검정으로 $\mathrm{F} / \mathrm{W}$ 역시 빨강색 상의는 무채색과의 배색이 많음을 알 수 있었다.

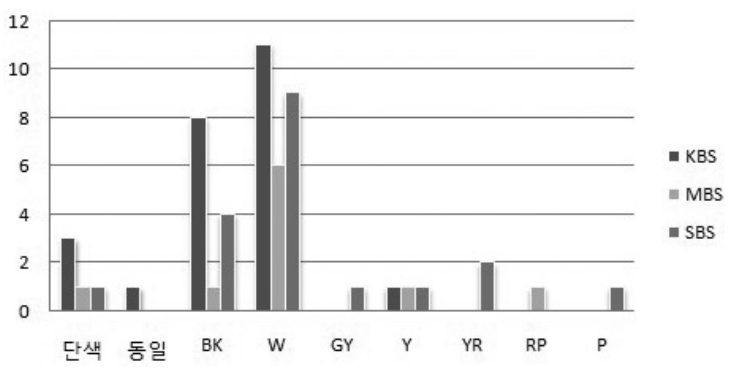

〈그림 7〉 F/W시즌 빨강색 상의의 배색 분포

\section{V. 요약 및 결론}

TV뉴스 여성 앵커들이 방송 시 착용한 빨강색 의상을 조 사하여 이미지, 색상분포, 배색의 특성을 고찰한 결과는 다 음과 같다.

빨강색이 이미지를 형성할 때는 색조의 영향보다는 빨강 색 자체가 가지고 있는 고유한 상징적 의미가 더 크게 작용 하는 것으로 나타났는데, 빨강색은 행복한-열정적 이미지로 
가장 많이 인지되고 있음을 알 수 있었다.

색상분포를 보면, 앵커들이 착용한 상의 전체 색상 중 무 채색을 제외하고 유채색 중에서는 빨강색 비율이 $32 \%$ 로 가 장 높았는데 평균 색상값은 $6.7 \mathrm{R}$ 이며, 명도는 4.5 로 중명도 에 속하고, 채도는 11.4 인 고채도로 나타났다. $\mathrm{S} / \mathrm{S}$ 시즌에는 빨강색 중 $\mathrm{v}, \mathrm{p}, \mathrm{vp}$ 톤이 가장 많이 사용되었고, $\mathrm{F} / \mathrm{W}$ 시즌에 는 s, lgr, l, gr, dl, dp 톤이 많이 사용되었다.

빨강색 상의와 매치시켜 입은 이너웨어에 대한 시즌별 배 색 분포를 살펴보면, 흰색과의 배색이 가장 많았고 다음이 검정색, 노랑색 순으로 나타났으며, 배색을 하지 않고 빨강 색만 착용한 경우도 $10 \%$ 가까이 되었다.

TV뉴스 여성 앵커가 착용한 의상색 중에서 무채색을 제 외하고 유채색 중에서 빨강색의 착용빈도가 가장 높은 것은 빨강색이 여성 앵커가 가지고 있는 열정적이고 자신감 넘치 는 당당한 이미지를 부각시킬 수 있기 때문으로 판단된다. 이러한 이미지는 시청자들로 하여금 전달하는 내용에 대한 관심과 신뢰도를 높일 수 있다고 생각된다. 이너웨어와의 배 색에서 가장 착용빈도가 높았던 것은 흰색과 검정으로 이는 화려한 이미지를 주면서도 이지적이고 세련된 여성미를 강 조할 수 있기 때문으로 분석된다.

앞으로 앵커의 의상은 선명한 단색, 단순한 디자인, 무늬 없는 소재를 가지고 유행에 대한 수용정도를 빠르게 반응하 여 철저한 의상 기획이 이루어져야 한다고 생각한다. 또한 다른 프로그램 의상과는 다르게 상체 위주의 단순한 디자인 과 얼굴형을 고려한 네크라인에 신경을 써야 한다는 특징을 갖고 있음을 알 수 있었다.

\section{참고문헌}

김민신(2007). TV 프로그램에 따른 방송인의 이미지 메이킹 에 영향을 미치는 요인, 숙명여자대학교 대학원 석사 학위 청구논문.

김민주(2002), 레드 마케팅, 서울: 이라크네. 김학성(1995), 디자인을 위한 색채, 서울: 조형사.

박성희(2004). 1980년대 이후 우리나라 TV 여성앵커의 패션 이미지 변화에 관한 연구, 성균관대학교 대학원 석사 학위 청구논문.

신수길, 박미자, 한광희, 황상민(1998). 감성 측정을 위한 우

리말 형용사의 의미구조, 한국감성과학회, 1(2), 10.

우석진(2005). 컬러리스트, 영진닷컴.

원경미, 김영인(2001), 국내 패션업계에서 활용하는 색명과 색채특성, 한국색채학회지, 15(1), 37-48.

이은경(2010), TV 뉴스 여성앵커 재킷의 색상 이미지 연구,

한국생활과학회지, 19(1), 149-156.

장하나(2003). TV 진행자들의 이미지 메이킹 연구, 원광대학 교 대학원 석사학위 청구논문.

하용득(1992). 한국의 전통색과 색채심리, 서울: 명지출판사. Breaem, H.(2002). 색의 유혹, 이영희(역), 서울: 예담출 판사. (1989년 원저발간).

Heller, E.(2002), 색깔의 힘, 김영희(역), 서울: 유로서적 (1992년 원저발간).

Kobayashi(1987). Ibid, 22-117.

Marshall(1988). Editions Limited. 186.

접 수 일 : 2009년 12월 29일
심사시작일 : 2010년 1 월 11 일
게재확정일 : 2010년 2월 5 일 